\title{
Globalization or glocalization - global trends, local effects of territorial reforms
}

\author{
Marian Kachniarz ${ }^{1, *}$ \\ ${ }^{1}$ Wrocław University of Environmental and Life Sciences, Institute of Space Economics, ul. \\ Grunwaldzka 55, 50-357 Wrocław, Poland
}

\begin{abstract}
.
Research background: The globalization processes are not only of an economic and cultural nature - but they also unify trends in the organization and management of administration, including at the local level. The idea of economization of administration was promoted in the broad stream of reforms described as New Public Management. It was often expressed as a postulate of the territorial reorganization of local governments. The reforms of these structures, motivated by the economies of scale, were to lead to the elimination of their allegedly too fragmented nature.

Purpose of the article: The questions about the global scale and effectiveness of these reforms resulted in the objectives of the study, which were formulated as follows:

- identification of the scope and scale of territorial reforms and assessment of their global character;

- evaluation of the real impact of these reforms in terms of economies of scale.

Methods: Methodologically, the work is the critical meta-analysis of the research results of consolidation reforms from many countries of the world. Findings \& Value added: The results lead to the conclusion that consolidation is a global trend. However, they do not unequivocally confirm the successes in achieving economies of scale in the provision of public services. The added value of this research is to draw attention to the fact that uncritical implementation of global trends does not automatically bring the assumed effects. It is necessary to apply in practice glocalization, i.e. critical adaptation of global solutions to local institutional conditions.
\end{abstract}

Keywords: territorial reforms; consolidation, globalization; glocalization, local government.

JEL Classification: $H 11 ; H 76 ; H 83 ; P 48$

\footnotetext{
* Corresponding author: marian.kachniarz@upwr.edu.pl
} 


\section{Introduction}

Institutional models of functioning of territorial public administration were developed in individual countries or regions according to individual social and political conditions and in specific historical contexts. As a result, within Europe itself, the size and competence of the basic units of public administration (municipalities) differ diametrically, and the science of public administration groups them into several separate models [1]. Although a municipality in different countries does not mean the same thing, there are noticeable efforts to unify its functioning not only in Europe but also globally. They consist of defining universal principles and standards of functioning and implementing reforms in the organization and management of local administration. Especially the idea of administration economization was promoted in the broad stream of reforms called New Public Management (NPM). It gained the title of a global trend of local administration reforms [2].

Thus, as it can be concluded, the processes of globalization are not only economic and cultural nature, but also influence the trends in the organization and management of administration, also at the local level. One of the manifestations of these reforms was the demands for a territorial reorganization of local governments. The reforms of these structures, motivated by economies of scale and increased efficiency. They were to eliminate their too fragmented character [3].

The typology of local government reforms may include financial, competence, legal, management, and territorial aspects. Out of this wide range of activities, the present research focuses on territorial reforms, consisting of changing local government structures by consolidating them and increasing their scale. Discussions on other types of territorial reforms (fragmentation, creation of two-tier units, the introduction of new levels) remain outside the scope of this paper.

The question arises here whether, first, it is reasonable to claim that the consolidation reforms of local government units are truly global in scale and, second, whether their local effects and effectiveness are universal on a global scale.

Based on such research questions, the goals that guide this paper are born:

- to determine the scope and scale of territorial reforms and assess their global character;

- to assess the real impact of these reforms in terms of economies of scale.

To achieve these goals, it was decided to critically analyze the results of research on consolidation reforms from many countries around the world. Although such consolidations have been carried out before, their particular intensity can be registered in the last two decades. The dynamics of the literature has also increased accordingly, so it has been decided to limit itself to studies of a meta-analysis nature - concerning many countries, excluding those that focus only on one country or region. To this end, the Web of Sciences resources from 2000 - 2020 was analyzed using a compilation of local government keywords, and consolidation of reforms. Out of 194 results, those that concerned individual countries and were not cross-sectional analyses of the effects of reforms were separated. In this way, 14 studies describing the nature of reforms and their effects were obtained. It was their analysis that served mainly to achieve the objectives of this article.

\section{Methodology and Data}

Local authorities are an integral part of democratic state authority, responsible for local development and the provision of a large number of local public services. Their important role in contemporary society is underlined in the main economic theories, including Oates' 
decentralization theory and the idea of fiscal federalism. One of the research trends that has undergone significant development in the last decade is the problem of the optimal size of the basic units of the country's territorial division. It is related to the economies of scale - the theory of the relationship between the size of a given unit and the effectiveness of its functioning. The importance of economies of scale in the manufacturing sector was first highlighted by Stigler [4]. The first applications to the public sector and local governments were made by Hirsch [5]; and Boyne [6]. They considered public administration as a production unit in the private sector. A thorough conceptualization of this issue, which took into account the specificity of the functioning of the public sector, was carried out by Houlberg [7] and Faulk and Hicks [8].

Reducing unit costs as scale increases does not usually have a linear trend. The large size of companies results in higher transaction costs that reduce economies of scale. If these costs outweigh the benefits, we may be dealing with the phenomenon of diseconomy of scale. In reality, therefore, the average cost-of-production curve takes the "U-shaped" form. It follows that at the lowest point of the "U-shaped" cost curve are at a minimum, inferring an optimum size of the production [9] If so, there should theoretically be an optimal size for the basic territorial division. Already in ancient times, Plato expressed the opinion that the size of a city should be about 25,000-30,000 residents [10]. This inspired contemporary researchers to search for such optimal values.

Unfortunately, despite the use of increasingly sophisticated research methods and large data sets, no such universal value was found. Many authors note that economic analyses cannot give hope for an accurate, optimal size. This is because local government services are not homogeneous and have their unique production features. It is difficult to determine the functionally optimum size of municipalities because different types of municipal activities have their optimum in quite different locations.

Many authors are careful in summarizing their ambiguous research findings. Some of them conclude that the differences in unit costs of small and large administrative units are insignificant. Several other factors have a greater influence on the evolution of this value. This situation reflects the fact that the question of the "optimum size of municipalities" is a typical "wicked problem" and does not have an absolute answer [11].

Despite these obvious reservations, politicians very often propose consolidation reforms as if they were the best panacea for the existing dysfunctions. Meanwhile, the problem of the territorial system is so important that its changes should be made with great caution. In a modernist perspective, each era creates new conditions and contexts, which may result in the establishment of adequate structures. As the conditions of the change are global, appropriate responses are also being unified. So here we have global trends of change. On the other hand, traditionalists believe that the permanence of structures is a value in itself [12]. This can be proved by the settlement system in Europe formed in the 12th-13th centuries, which survived many socio-economic transformations (agrarian and industrial revolution, urbanization, etc.). This should lead to a reflection on the implementation of universal methods and the need to adapt them to local conditions. It is therefore a typical process of glocalization.

\section{Results}

The end of the 1990s and the beginning of the 21st century is a new period of intensifying territorial reforms in various European countries, for example, in Greece, Macedonia, Georgia, and Denmark. In several other countries (UK, Estonia, Finland, the Netherlands, Iceland, Germany, etc.) we saw a more gradual process or "silent revolution" where there was no single, clear moment of reform, but several mergers took place almost every year.

Another wave of consolidation reforms followed the financial and economic crisis in 2008. This included I .a. Latvia (2009), Greece (2011), Luxembourg (2011), Ireland (2014), 
Turkey (2014), and Albania (2015). Moreover, in the process of reforms that could lead to a reduction in the number of municipalities soon, are also: Armenia, Estonia, Italy, Norway, and Ukraine. In Norway, for example, the government expects that the number of municipalities can be reduced from over 400 to around 100. Until now (summer 2019), the number of Norwegian municipalities has decreased from 428 to 354 . The vast majority of mergers were voluntary, but in a dozen or so cases, this was a central decision despite local objections. As a result, the balance of changes after 1990 indicates a decreasing number of municipalities in Europe. The total number of municipalities in 40 European countries decreased from 116000 in 1990 to around 100000 in 2018, which was a 16\% reduction [13].

Also outside Europe, mergers of municipalities are the main form of local government reform in most developed countries. Many OECD countries have planned or implemented mergers of local governments in the last 20 years. An example is Japan, where after 1999 the central government promoted mergers of local governments. As a result, 649 mergers of municipalities have taken place here, most of them (83\%) in 2004-2005, leading to a reduction in the number of municipalities from 3,232 in 1999 to 1,718 in 2014. The wave of municipal mergers from 1999 to 2010 is called Great Heisei Municipal Consolidation. At the same time, the consolidation of self-government units in South Korea was carried out, which led to the country having the largest size of basic territorial division units among OECD countries (224 thousand inhabitants) [14].

An example of consolidation reforms in Australia and New Zealand is very well developed. They were undertaken on the wave of NPM-motivated reforms in which both countries were recognized as leaders. In New Zealand local government is no stranger to council amalgamation, having experienced radical restructuring in 1989 when about 700 councils and special purpose bodies were merged into 86 local authorities. In Australia, consolidation was carried out in several waves. Those carried out after the recent economic crisis reduced the number of municipalities from 841 to 556 [15].

In the 1990s and 2000s, the Canadian government committed itself to one of the largest consolidation programs in the country. In 1995, there were 850 municipalities, but by 2000 , the number had been reduced to 444. Many changes occurred in agglomerations (including Toronto, Montreal, Quebec) where the two-tier metropolitan government of Toronto was liquidated and transformed into a single-tier government. In the USA, these processes take place mainly in the form of city-county consolidations (two-tier). They mainly concern urban areas where the central unit takes over the tasks of other levels of local government. Horizontal consolidations of municipalities are slightly less important, although the authorities of individual states strongly support them [16].

With the modernization and construction of welfare state societies, the size of local government units inherited from earlier periods was often considered too small to capture the economies of scale in public service delivery.

Thus, projects to merge municipalities were carried out in almost all developed countries. These reforms have therefore been carried out worldwide, giving them a global dimension. It should be mentioned, however, that not all countries have submitted to these processes. It is clear that, for example, poorer countries (Africa, Pd-Wsch Asia), or those that liberated themselves from previous regimes (Central and Eastern Europe, Central America, and South Africa) maintained the size of their municipalities or even reduced them. In these countries, democratization meant the fragmentation of basic territorial units. Over time, however, consolidation tendencies were also revived in these groups of countries.

The large scope of consolidation reforms is, of course, an excellent testing ground for researches on their effects. While earlier this issue did not attract much interest from scientists, in the last two decades, the situation has changed significantly. The number of studies on the impact of municipal territorial reforms has been steadily growing. There have been many papers presenting the results of meta-analyses of an international character. 
Noteworthy were the studies comparing many countries, which included works by Walker and Andrews [17], Koprić et al. [18], but also Kuhlmann and Bogumil [19]. However, the most comprehensive meta-analyses were presented by Swianiewicz et al. [20], Tavares [21], Schwab at al. [22], Blum-Hansen et al. [23], and Gendźwiłł et al. [24]. The first of these studies thoroughly diagnose consolidation reforms in European countries and presents the results of studies on their consequences. Tavares presents a synthesis of empirical literature published over the last 20 years, organizing the effects of mergers into three categories: economic efficiency and cost savings, management implications, and democratic results. A study edited by Schwab, Bouckaert, and Kuhlmann identify the effects of local public sector reforms from an international, comparative perspective, to explain these approaches/effects and to draw lessons for future policymaking.

\section{Discussion and conclusions}

With this amount of research, it can be expected that the effects of consolidation and increase in the scale of operations of entities will be very well recognized. All the more so because the conviction that "bigger is better" belongs to the so-called intuitive knowledge, deeply rooted in the minds of many representatives of administration and politics. However, a review of the meta-analyses presented above leads to a surprising conclusion. Focusing on the economy of scale, expressed in economic values, these studies do not lead us to consistent conclusions - scientists are far from unanimous in this respect.

The surprising effect of these analyses is the lack of confirmation of the seemingly common-sense view that larger units are more efficient. The authors of these studies carefully summarize the results of their research as ambiguous and far from confirming the hypothesis of "economies of scale". Some of them state that consolidation has not resulted in relatively cheaper operation, while others state that the differences in unit costs between small and large units are negligible. Especially when compared with the costs of reforms undertaken and the losses resulting from economies of scale. There are even opinions that the costs of memory disorders in institutions and the costs of employee opportunism are clearly underestimated by the authors of the reforms and far outweigh the effects of consolidation. There is also a specific effect of the "upward equation" in which both remuneration and services are at the highest level of the consolidated entity. In such cases, it is not even difficult to find the disefect of scale, where the operating costs of large municipalities are much higher than those of smaller ones. Such negative effects are particularly visible in those categories of services that are labor-intensive (social services). Most often, a decrease in unit costs of services, along with an increase in the scope of their provision, is recorded in infrastructure services. At this point, it is worth noting that each type of service may have its optimum in a different place. Therefore, it is difficult to determine the optimal size for their diverse package. To this extent these are opinions recommending changes inside the units, increasing the freedom of organization and flexibility of service provision, not border reforms.

Therefore, if the results of the research do not confirm the relationship between the effectiveness and size of a local government unit, why is this belief so strong in the public debate? Why do many representatives of organizational and management sciences accept this statement a priori? The specificity of the public sector means that theories that work well in production activities are not fully applicable to public administration. They are subject to much more diverse conditions, defined as institutional norms. The result, among others, from the structure of management, tendency to atomize units and organizational divisions, disturbances in the flow of information, aspiration to accumulate resources, and suppression of the main goals and principles of the unit's functioning.

The first problem is to determine the point at which further growth of the unit may already bring disadvantages of scale. This situation occurs when the size of a unit causes increased 
transaction costs. As analyzed studies show, consolidation processes are a popular way to implement reforms, regardless of the initial size of units. Such demands are made and substantiated, both in countries with high fragmentation (France, Czech Republic, Slovakia) and in states with very large entities (Denmark, England, Ireland, South Korea). Meanwhile, many studies indicate that too much fragmentation may generate additional costs, but also the optimal size scale may be relatively low - between 8-20 thousand inhabitants. Perhaps the optimum, behind which scale disadvantages appear, is located at a relatively low level. Unnoticed by those who seek it always in the largest units. In this case, the term 'large' would take on relative importance.

The second element explaining the lack of clear results of these studies may be the complex structure of services provided by local governments. The impact of economies of scale in particular areas may be different. As a result, there may even be negative couplings in which economies of scale, e.g. from the provision of a selected municipal service, will be eliminated by disseffects in a service qualified to the group of social or administrative services.

A very important element is the social control - more direct in smaller units. Large structures are much more abstract for local communities, which in turn increases the anonymity of the officials working there. As a result, the whole administration becomes less transparent for the local community. It also hinders the direct supervision of managers, making it impossible for them to strictly assess the current functioning, as well as the legitimacy and directions necessary to make changes.

These conclusions show the importance of local institutional conditions. The automatic adoption of reform patterns can produce different results in different places. This fact should serve as a warning against thoughtless changes in local administrative structures. They should be preceded each time by a detailed and interdisciplinary analysis of the conditions of a given country or region. Therefore, we are dealing with a situation where global and universal solutions can bring different results on a local scale. Therefore, the need to adapt them to the local conditions bears the signs of a glocalization process.

Megatrends related to digitalization, globalization of economic activity, and urbanization contribute to strengthening the role of sub-national governments. Globalization, eliminating barriers to the flow of capital and ideas between countries, also means freedom of penetration within countries. It means that cities can compete for foreign direct investment, a task once monopolized by central governments. Urbanization and metropolization processes support the trend of increasing the scale of local units. The results of the review of the scope of consolidation reforms in the world lead to the conclusion that we are dealing with a global trend. Although it is not universal, it seems to be part of the implementation of management reforms in countries with higher levels of development.

These conclusions fulfill the first objective of this study, defined in the introduction, concerning the characteristics of the scope and scale of consolidation reforms in various countries of the world. The question of the future of these reforms directions remains open, especially in countries with lower levels of development. The link with other megatrends, such as the development of digital communications and the detoralization of public services, allows us to make a cautious assumption that this direction of reform will be imitated in subsequent countries. The deepening of globalization in this area is an interesting subject of further research.

On the other hand, globalization has revived local cultural identities, resulting in the need to adopt reforms more to local conditions. In the context of the democratic crisis, many countries have also emphasized the role of local governments as the closest level of authority to citizens and a way to better reflect their needs. The "local" approach may be a response to global solutions, which indicates the importance of the glocalization process. 
It takes on importance in the light of the research results shown in the article, which, to put it mildly, do not confirm the economies of scale in the provision of public services. This part of the conclusions fulfills the second objective of this research. The added value of these studies is to draw attention to the fact that uncritical implementation of global trends does not automatically produce the expected results. It is necessary to apply in practice glocalization, i.e. critical adaptation of global solutions to local institutional conditions. Due to this ambiguity of the effects of consolidation reforms in the world, deepening this direction of research seems to be a very attractive direction for further in-depth research.

\section{References}

1. Mazur, S., Kopyciński, P. (2018). Public Policy and the Neo-Weberian State. Oxford: Routledge.

2. Pollitt, C., Bouckaert, G. (2011). Public Management Reform: A Comparative Analysis - New Public Management, Governance, and the Neo-Weberian State, Oxford: Oxford University Press.

3. Babczuk, A., Kachniarz, M., Piepiora, Z. (2017). Work efficiency of local government. In P. Jedlicka, P. Maresova, J. Soukal (Eds.), Proceedings of the 15th International Scientific Conference on Hradec Economic Days, Vol 7(1), 2017 (pp. 20-28). Hradec Kralove: University of Hradec Kralove.

4. Stigler, G.J. (1958). The Economies of Scale. The Journal of Law \& Economics, 1, 5471.

5. Hirsch, W. (1959). Expenditure Implications of Metropolitan Growth and Consolidation. The Review of Economics and Statistics, 41(3), 232-241.

6. Boyne, G. (1995). Scale, performance, and the New Public Management: An empirical analysis of local authority services. Journal of Management Studies, 33(6), 809-826.

7. Houlberg K. (2010). Municipal size, economy, and democracy. In: P. Swianiewicz (Eds.), Territorial Consolidation Reforms in Europe, Budapest: LGI - Open Society Institute.

8. Faulk, D., Hicks, M. (2011). Local Government Consolidation in the United States. Amherst, NY: Cambria Press.

9. Williamson, O. (1967). Hierarchical Control and Optimum Firm Size. Journal of Political Economy, 75(2), 123-138.

10. Swianiewicz, P. (2010). If Territorial Fragmentation is a Problem, is Amalgamation a Solution? An East European Perspective. Local Government Studies, 36(2), 183-203.

11. Swianiewicz, P., Łukomska, J. (2017). Is Small Beautiful? The Quasi-Experimental Analysis of the Impact of Territorial Fragmentation on Costs in Polish Local Governments. Urban Affairs Review, 55(3), 832-855.

12. Przybyła, K., Kachniarz M., Hełdak M. (2018). The Impact of Administrative Reform on Labour Market Transformations in Large Polish Cities. Sustainability, 10(8), 1-15.

13. Dollery B., Kitchen H., McMillan M., Shah A. (2020). Structural Reform: Municipal Mergers. Local Public, Fiscal and Financial Governance. Cham: Palgrave Macmillan.

14. Machimura T. (2016). Why Half the Municipal Governments Disappear Under a National Mergers Policy? Changing Local Bases in "Globalizing" Japan. In: E. Healy, D. Arunachalam, T. Mizukami (Eds.) Creating Social Cohesion in an Interdependent World. New York: Palgrave Macmillan. 
15. Dollery, B.E., Drew, J. (2017). Chalk and Cheese: A Comparative Analysis of Local Government Reform Processes in New South Wales and Victoria. International Journal of Public Administration, 41(11), 847-858.

16. Sancton, A. (2000) Merger Mania: The Assault on Local Government. MontrealKingston: McGill-Queen's University Press.

17. Walker R.M., Andrews R. (2013). Local government management and performance: A review of evidence. Journal of Public Administration Research and Theory, 25(1), 101 133.

18. Koprić, I., Wollmann, H., Marcou, G. (2017). Evaluating Reforms of Local Public and Social Services in Europe: More Evidence for Better Results (Governance and Public Management), Cham: Palgrave Macmillan.

19. Kuhlmann, S., Bogumil, J. (2018). Performance measurement and benchmarking as 'reflexive institutions' for local governments: Germany, Sweden, and England compared, International Journal of Public Sector Management, 31(4), 543-562.

20. Swianiewicz P, Gendzwill A., Zardi A. (2017). Territorial reforms in Europe. Does size matter? Brussels: Council of Europe, Centre of Expertise for Local Government Reform.

21. Tavares A.F. (2018). Municipal amalgamations and their effects: a literature review. Miscellanea Geographica - Regional Studies On Development, 22(1), 5-15.

22. Schwab, Ch., Bouckaert, G., Kuhlmann, S. (2017). The Future of Local Government in Europe Lessons from Research and Practice in 31 Countries. Baden-Baden: Nomos Verlagsgesellschaft.

23. Blom-Hansen, J., Houlberg, K., Serritzlew, S., Treisman, D. (2016). Jurisdiction Size and Local Government Policy Expenditure: Assessing the Effect of Municipal Amalgamation. American Political Science Review, 110(4), 812-831.

24. Gendźwiłł, A., Kurniewicz, A., Swianiewicz, P. (2020). The impact of municipal territorial reforms on the economic performance of local governments. A systematic review of quasi-experimental studies, Space and Polity, 1-20. 